\title{
Análise espacial da precipitação pluviométrica na microbacia do Rio Carnaíba de dentro e seu entorno no semiárido baiano entre 2009 a 2014
}

\author{
Analysis of rainfall in the river basin of carnaíba of dentro and its \\ surrounding in semiárido baiano- 2009 the 2014
}

\begin{abstract}
Carlos Magno Santos Clemente
Formado em geografia e Mestre em Ciências Biológicas. Faculdade Guanambi - FG/Observatório FG do Semiárido Nordestino carlosmagnoclemente@gmail.com

Deborah Marques Pereira

Formada em Direito e mestre em desenvolvimento social. Faculdade Guanambi - FG/Observatório FG do Semiárido Nordestino deborah.mp.fg@gmail.com

Thomas Leonardo Marques de Castro Leal Engenheiro ambiental, especialista em segurança do trabalho. Faculdade Guanambi - FG/Observatório FG do Semiárido Nordestino thomasmdcl@gmail.com

Maycon Fagundes Teixeira Reis Doutor em Engenharia Agrícola. Faculdade Guanambi - FG/ Universidade Federal de Sergipe (Campus Sertão). mayconftreis@hotmail.com
\end{abstract}

\section{Resumo}

A microbacia do rio Carnaíba de Dentro tem como cenário regional o semiárido baiano. Essa região é caracterizada por condições climáticas peculiares no contexto brasileiro, bem como, estiagens de chuvas em anos consecutivos. Desse modo, objetivou-se com a pesquisa compreender a distribuição da precipitação pluviométrica na microbacia hidrografia do rio Carnaíba de Dentro e seu entorno entre os anos de 2009 a 2014. Foram delimitadas 5 estações meteorológicas dentro e no entorno e o método geoestatístico utilizado foi a krigagem. Entre os anos de 2009 a 2014, os valores de precipitação anual acumulada variaram de 291,3 a $1.058 \mathrm{~mm}$. A estação localizada no município de Carinhanha registrou elevados valores de precipitação $(1058 \mathrm{~mm})$ e baixos indicadores foram registrados na divisa de Minas Gerais com Bahia (estação Espinosa). Com isso, as análise indicam uma estiagem de 5 a 7 meses entre abril a outubro e uma distribuição irregular espaço-temporal na microbacia do rio Carnaíba de Dentro nos anos analisados.

Palavras-chave: Análise Espacial; Geoprocessamento; INMET; Estação Meteorológica.

\begin{abstract}
The watershed of Carnaíba river has a regional setting the Bahian semi-arid. This region is characterized by peculiar climatic conditions in the Brazilian context, as well as drought rains in consecutive years. Thus, the objective of this research is to understand the distribution of the pluviometric precipitation in the watershed of Carnaíba river and its surroundings between the years of 2009 and 2014. Five weather stations were defined inside and in its surroundings and the geostatistical method was kriging. Between the year of 2009 and 2014, the values of annual precipitation accumulated ranged between 291,3 and $1.058 \mathrm{~mm}$. The station located in the city of Carinhanha recorded elevated values of precipitation $(1.058 \mathrm{~mm})$ and low indicators were recorded on the border with Minas Gerais (Espinosa Station). Thereby, the analyses indicate an drought of 5
\end{abstract}


to 7 months between April and October and a distribution irregular space-time in the watershed of Carnaíba River in the analyzed years.

Keywords: Spatial Analysis; GIS; INMET; Weather Stations.

\section{INTRODUÇÃO}

A análise da distribuição da precipitação pluviométrica em uma bacia hidrográfica é um mecanismo proeminente para nortear medidas para o uso racional dos recursos hídricos. Nesse contexto, o entendimento do regime de chuvas se torna artificio para o planejamento econômico e a conservação do ambiente natural (SIMONI et al, 2014). Além disso, a compreensão do regime pluviométrico em determinada região são indicadores para constituição de um calendário e a implementação de projetos para o desenvolvimento agrícola (SILVA et al, 2011). No caso de regiões semiáridas, o uso e manejo dos recursos hídricos são mecanismos para a conivência nessa região brasileira (SILVA, 2012).

A concepção de bacias hidrográficas como unidade de gestão territorial é uma alternativa para harmonia entre as concepções sociais, econômicas e naturais (PORTO; PORTO, 2008). No caso da precipitação se torna relevante, já que o regime de chuva tem relação direta no ciclo hidrológico e nas diversas utilidades humanas.

Outro fator que contribuem para compreensão da dinâmica espaço-temporal dos recursos hídricos são as análises espaciais. O termo análise espacial que significa um conjunto de métodos analíticos fundamentado em informações relativas à localização dos objetos no espaço agrupado as informações geográficas diversas (CÓSME, 2012).

As análises espaciais são incorporadas ao conceito das Geotecnologias. Essa que congrega técnicas como o Sensoriamento Remoto, Geoprocessamento (Sistema de Informação Geográfica SIG, Cartografia Digital, Processamento Digital de Imagem - PDI); Sistema de Posicionamento Global - GPS; Geodésica; e Topografia Clássica (LEITE; ROSA, 2002).

Com isso, objetivou-se com esta pesquisa compreender a distribuição espacial da precipitação pluviométrica na microbacia hidrográfica do rio Carnaíba de Dentro, semiárido baiano, no período de 2009 a 2014. Essas análises basearam-se nas estações meteorológicas das normais climatológicas do Instituo Nacional de Meteorologia - INMET.

A microbacia do rio Carnaíba de Dentro se insere no contexto regional do semiárido baiano. A região apresenta em seu histórico de ocupação períodos de estiagem e baixos indicadores de precipitação (SANTOS et al, 2012). Também o semiárido brasileiro carrega em seu histórico de ocupação territorial um drama social e interpretações superficiais ambientais da região (AB’SABER, 1999). Assim, a utilização dos recursos hídricos de maneira racional e analisar o 
regime hídrico da microbacia do rio Carnaíba de Dentro proporcionarão informações para melhor gestão socioambiental.

\section{METODOLOGIA}

\section{1. Área de estudo}

A microbacia hidrográfica do Rio Carnaíba de Dentro se insere entre as coordenadas geográficas $43^{\circ} 11^{\prime} 29^{\prime}$ O $\mathrm{O}, 13^{\circ} 58^{\prime} 39^{\prime}$ ' S e $42^{\circ} 28^{\prime} 47^{\prime}$ O, $14^{\circ} 32^{\prime} 14^{\prime \prime} \mathrm{S}$, com uma área total de $2.576,53 \mathrm{~km}^{2}$. A microbacia integra a sub-bacia hidrográfica do rio das Rãs e bacia do Rio São Francisco. Ainda, a microbacia, localiza-se no semiárido baiano e microrregião geográfica do Instituto Brasileiro de Geografia e Estatística (IBGE) de Guanambi (BA) (Figura 1).

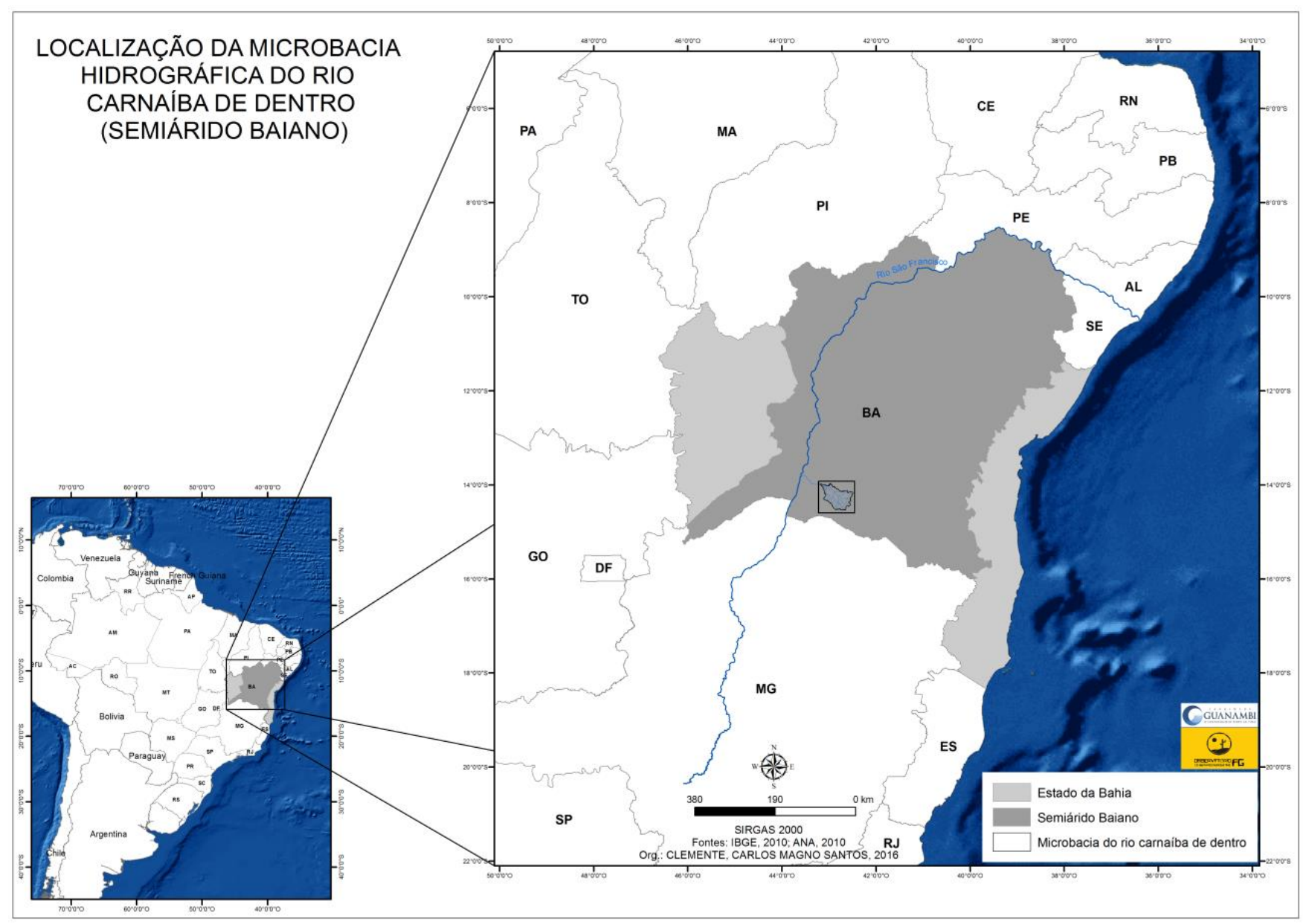

Figura 1. Localização da Microbacia Hidrográfica do Rio Carnaíba de Dentro (BA) Org.: CLEMENTE, Carlos Magno Santos, 2016

A microbacia do rio Carnaíba de Dentro apresentam 5 (cinco) limites municipais inseridos, parcialmente, no contorno natural. Em um total de $2.576,53 \mathrm{~km}^{2}$ da microbacia, a distribuição geográfica municipal se conFigura da seguinte forma: Guanambi 43,94\%; Palmas de Monte Alto 19,07\%; Candiba 15,77\%; Pindaí 14,35\% e Caetité 6,84\%. Em relação área total de cada município 
supracitado inserido na microbacia, seguem os seguintes percentuais: Candiba 97\% (área municipal total 433,642 km²), Guanambi 87\% (área municipal total 1.272,367 km²), Pindaí 60\% (área municipal total $628,471 \mathrm{~km}^{2}$ ), Palmas de Monte Alto $19 \%$ (área municipal total $2.562,816 \mathrm{~km}^{2}$ ) e Caetité 6\% (área municipal total 2.651,537 km²). (IBGE, 2010). (Figura 2).

As cidades de Guanambi, Candiba e Pindai estão inseridas na microbacia do rio Carnaíba de Dentro, com uma população urbana de 62.565, 7.725 e 4.319 habitantes, respectivamente, total de 74.609 (IBGE, 2010). Além disso, no interflúvio da bacia, conFiguram-se as unidades de conservação de proteção integral refúgio de vida silvestre da Serra dos Montes Altos e o parque estadual da Serra dos Montes Altos, como apresenta a Figura 2.

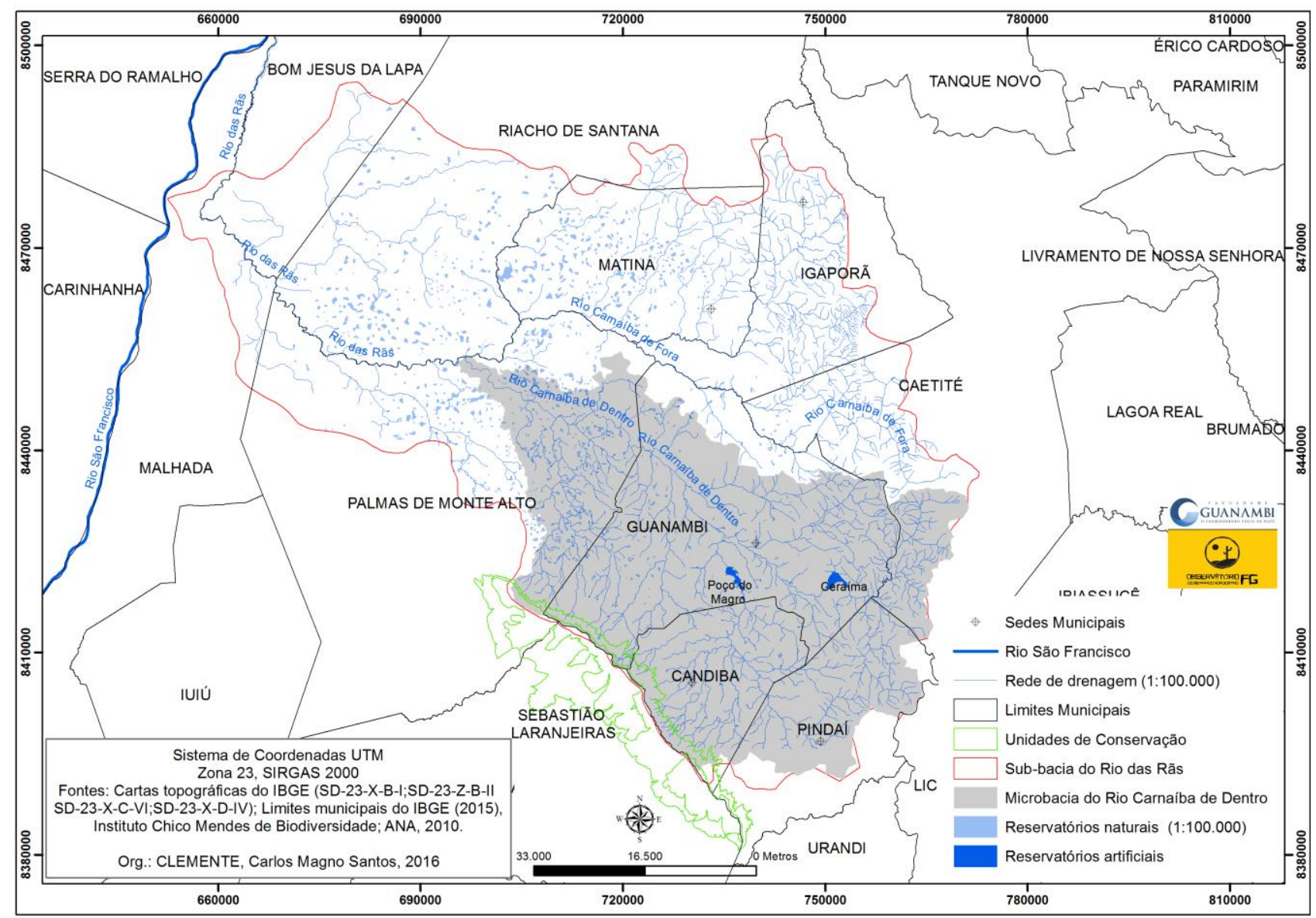

Figura 2. Localização da Unidade de Conservação, rede de drenagem, limites municipais e limites hidrográficos. Org.: CLEMENTE, Carlos Magno Santos, 2016

De acordo com o Programa de Conservação e utilização Sustentável da Diversidade Brasileira - PROBIO, em seu sub projeto relativo ao levantamento da cobertura vegetal e do uso do solo do bioma caatinga (escala de 1:250.000), a microbacia do rio Carnaíba de Dentro apresenta as seguintes fitofisionomias: Floresta Estacional Decidual - FED, Savana (Cerrado), Savana Estépica (Caatinga) e o Contato entre Vegetações. A Caatinga tem como características formações de vegetações caducifólias xerófilas, predominância de cactáceas e bromeliáceas, já o Cerrado apresenta como propriedades vegetações arbóreo ou arbustivo e um "tapete" herbáceo 
(JACOMINE, 1979). A FED distingue pelo "estrato superior formado de macro e mesofanerófítos predominantemente caducifólios, com mais de 50\% dos indivíduos despidos de folhagem no período desfavorável" (IBGE, 2012).

A Figura 3 destaca os tipos de vegetação na microbacia do rio Carnaíba de Dentro e seu entorno em uma escala de 1:250.000.

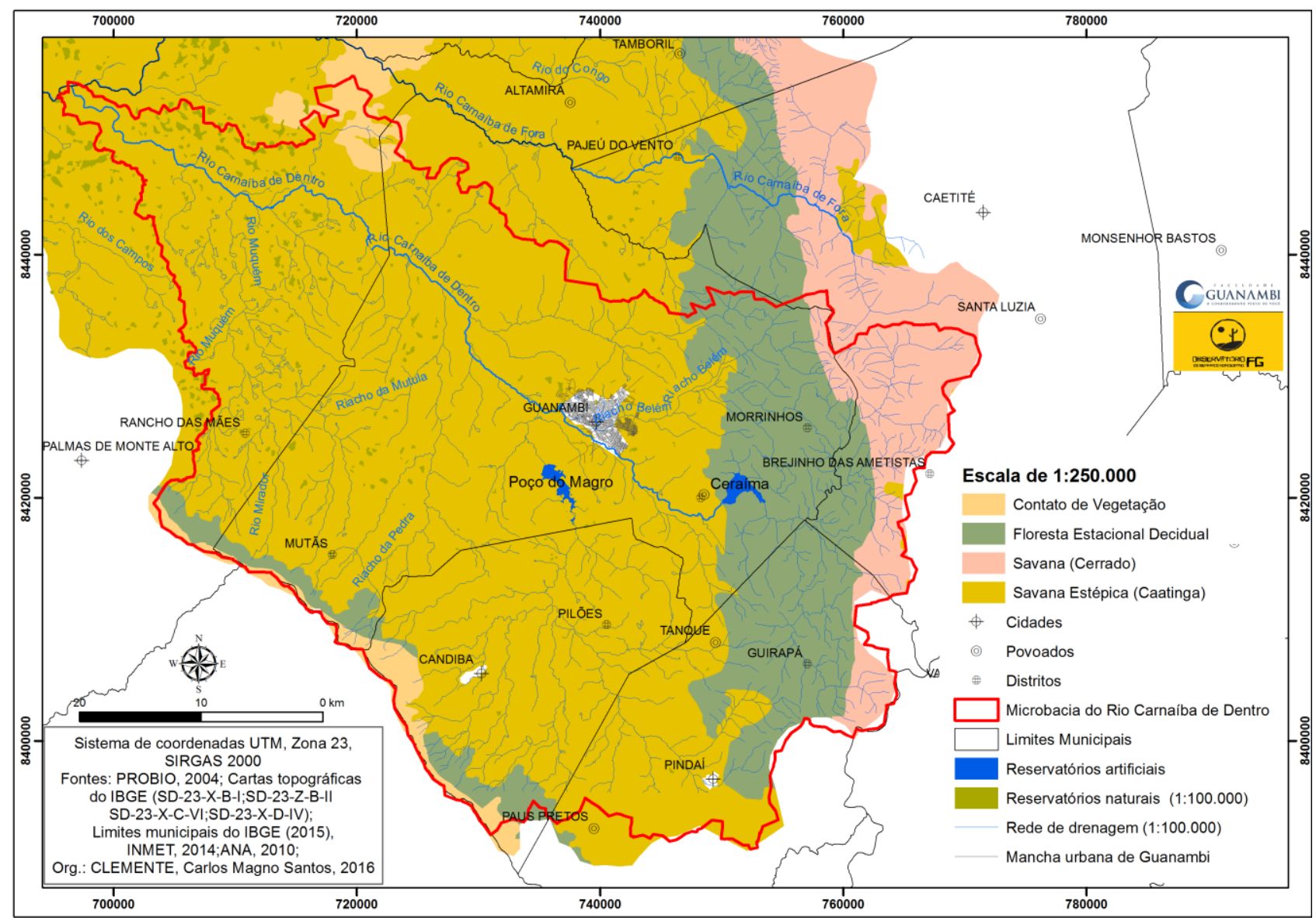

Figura 3. Tipos de vegetação da microbacia do Rio Carnaíba de Dentro (Escala de 1:250.000) Org.: CLEMENTE, Carlos Magno Santos, 2016

\subsection{Materiais e métodos}

Para o desenvolvimento da pesquisa foram adquiridos dados de precipitação pluviométrica do Instituo Nacional de Meteorologia (INMET) dos anos de 2009, 2010, 2011, 2012, 2013 e 2014. Para a escolha das datas levaram-se em consideração o ano e o mês de implantação das estações meteorológicas e a consistência dos dados. O ano inicial, 2009, foi delimitado devido a estação meteorológica de Guanambi dispor de dados a parti desta data.

Foram selecionadas as estações disponibilizadas pelo INMET dentro e no entorno da microbacia hidrográfica do rio Carnaíba de Dentro, em específico, 5 (cinco) estações meteorológicas. As estações localizam-se nos municípios de Bom Jesus da Lapa/BA; Caetité/BA; 
Carinhanha/BA, Guanambi/BA; e Espinosa/MG. (Figura 04). Também, foi as normais climatológicas do INMET que seguem as instruções da Organização Meteorológica Mundial OMM, que considera dados climáticos em um período aproximado de 30 anos (1961 a 1990) (INMET,1992).

Foram utilizadas as cartas topográficas do IBGE, SD-23-X-B-I; SD-23-Z-B-II; SD-23-X-CVI;SD-23-X-D-IV, para nortear as nomenclaturas e localização da rede de drenagem da bacia e seu entorno. Para Modelo Digital de Elevação - MDE foram utilizados dados do Shuttle Radar Topography Mission - SRTM, 1 arc. segundo (30 metros). A Figura 4 apresenta a rede de drenagem, a localização das estações pluviométricas e o radar SRTM.

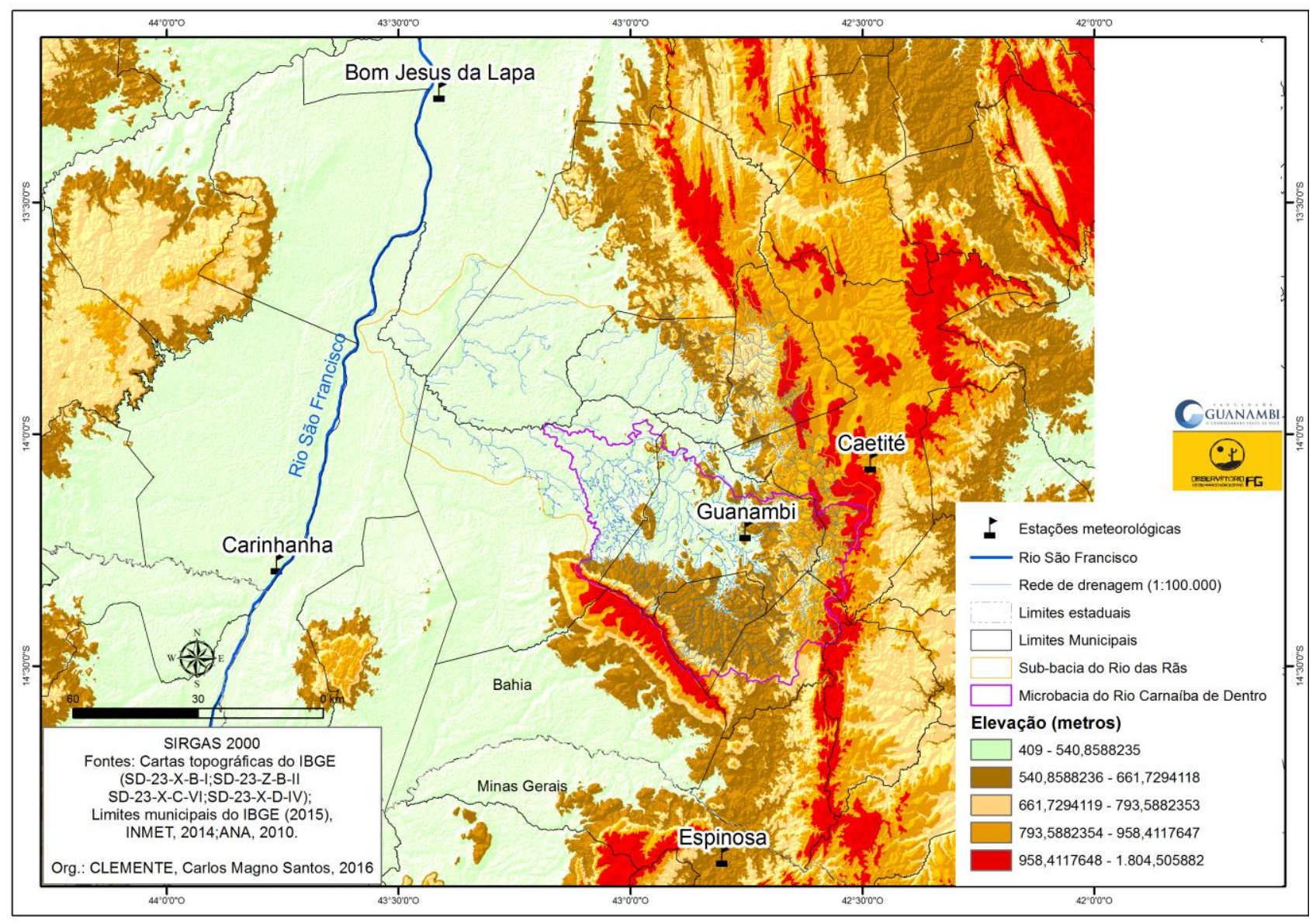

Figura 4. Localização das estações meteorológicas Org.: CLEMENTE, Carlos Magno Santos, 2016

Com a utilização do Geoprocessamento realizou-se a espacialização das estações, por meio de coordenadas fornecidas pelo INMET, organização em banco dados alfanuméricos georreferenciados e a adequação cartográfica do mapa de normais climatológicas do INMET.

Através do método geoestatítico da krigagem realizou-se a interpolação dos dados de precipitação anual de 2009 a 2014. As interpolações considerando as amostras dos dados de precipitações acumuladas, localização e as distâncias entre as estações (VALERIANO; ROSSETTI, 2012). Esse método tem como desígnio relacionar as semelhanças ou diferenciações das 
observações de acordo com as distâncias no espaço geográfico, isso permite a constituição de isolinhas de áreas não observadas (VALERIANO; ROSSETTI, 2012). O método geoestatítico que ameniza os erros e auxilia na robustez dos resultados (SIMONI et al, 2014).

Para delimitação da microbacia do rio Carnaíba de Dentro utilizaram-se o processo de delimitação de bacias hidrográficas automático, desenvolvido pela ESRI (2014). O seguinte método foi desenvolvido: "preenchimentos das depressões ("fill sinks"), direção de fluxo ("flow direction"), fluxo acumulado ("flow accumulation") e delimitação de bacias ("Watershed")" (DIAS et al., 2004; SOBRINHO et al. 2010).

Para a modelagem em 3D da área de estudo foi realizada a justaposição dos dados do SRTM com a imagem do ano de 2014 do satélite Landsat 8. Também, foram inseridas coordenadas do mapa das normais climatológicas disponibilizado pelo INEMT com o intuito de analisar as faixas de precipitação no contexto do semiárido brasileiro e da área do estudo. Foi vetorizado a faixa de precipitação abaixo $1.050 \mathrm{~mm}$, intervalo que insere a área de estudo, e feito o recorte espacial para semiárido brasileiro. Os procedimentos operacionais foram realizados no software ArcGIS 10.2.2, nas plataformas ArcMap e ArcScene.

\section{RESULTADOS E DISCUSSÃO}

De acordo com o mapa das normais climatológicas do INMET, aproximadamente, $70 \%$ da área do semiárido brasileiro apresentam-se precipitação acumuladas anuais menores $1.050 \mathrm{~mm}$. No caso da área de estudo, as normais climatológicas indicam uma variação de 650 a 1.050 mm de precipitação acumulada anual, valores peculiares à região semiárida.

Em comparação com outras regiões brasileiras, como o caso do Norte do Brasil (região amazônica), normais climatológicas alcançaram precipitação acumulada anual de $2.050 \mathrm{~mm}$ a 3.450 milímetros anuais e o sul do Brasil (Sudoeste Paraná e Oeste de Santa Catarina) registros de 1.850 $\mathrm{mm}$ a $2.050 \mathrm{~mm}$. Nesse contexto, a comparação evidência a precipitação pluviométrica destoante do semiárido em relação a outras regiões do Brasil (INMET, 1992).

Os dados indicaram baixos valores de precipitação nos anos de 2014 (291 mm), 2012 (449,4 mm), 2011 (318 mm) e 2010 (448,4 mm), na estação meteorológica de Espinosa (MG), divisa dos estados de Minas Gerais e Bahia em relação a outras regiões brasileiras, como supracitadas. Também esses valores mencionados de precipitação estão abaixo das normais climatológicas da região (mínimo de $650 \mathrm{~mm}$ ). Observaram-se na estação meteorológica localizada dentro da Bacia do Rio Carnaíba de Dentro, valores anuais abaixo das normais climatológicas em seu valor mínimo, nos anos de $2011(585,21 \mathrm{~mm}), 2012(584,13 \mathrm{~mm})$ e $2011(585,21 \mathrm{~mm})$. A Figura 05 apresenta a precipitação acumulada anual da microbacia do rio carnaíba de dentro e seu entorno. 
Entretanto, foram verificados altos valores de precipitação acumulada, em relação aos outras estações meteorológicas analisadas, no entorno das cidades de Carinhanha (BA) e Iuiú (BA). Detectaram-se no ano de 2009, na estação meteorológica de Carinhanha (BA), precipitação acumulada de $1.058 \mathrm{~mm}$. Esse valor ultrapassa as normais climatológicas do INMET em seu valor máximo para a região $(1.050 \mathrm{~mm})$. Na borda Nordeste do interflúvio da microbacia hidrográfica, a estação meteorológica de Caetité, notaram-se registros significativos de precipitação acumulada, principalmente no ano de $2009(809 \mathrm{~mm})$. A Figura 5 destaca a espacialização da precipitação pluviométrica anual na microbacia do rio Carnaíba de Dentro e seu entorno.

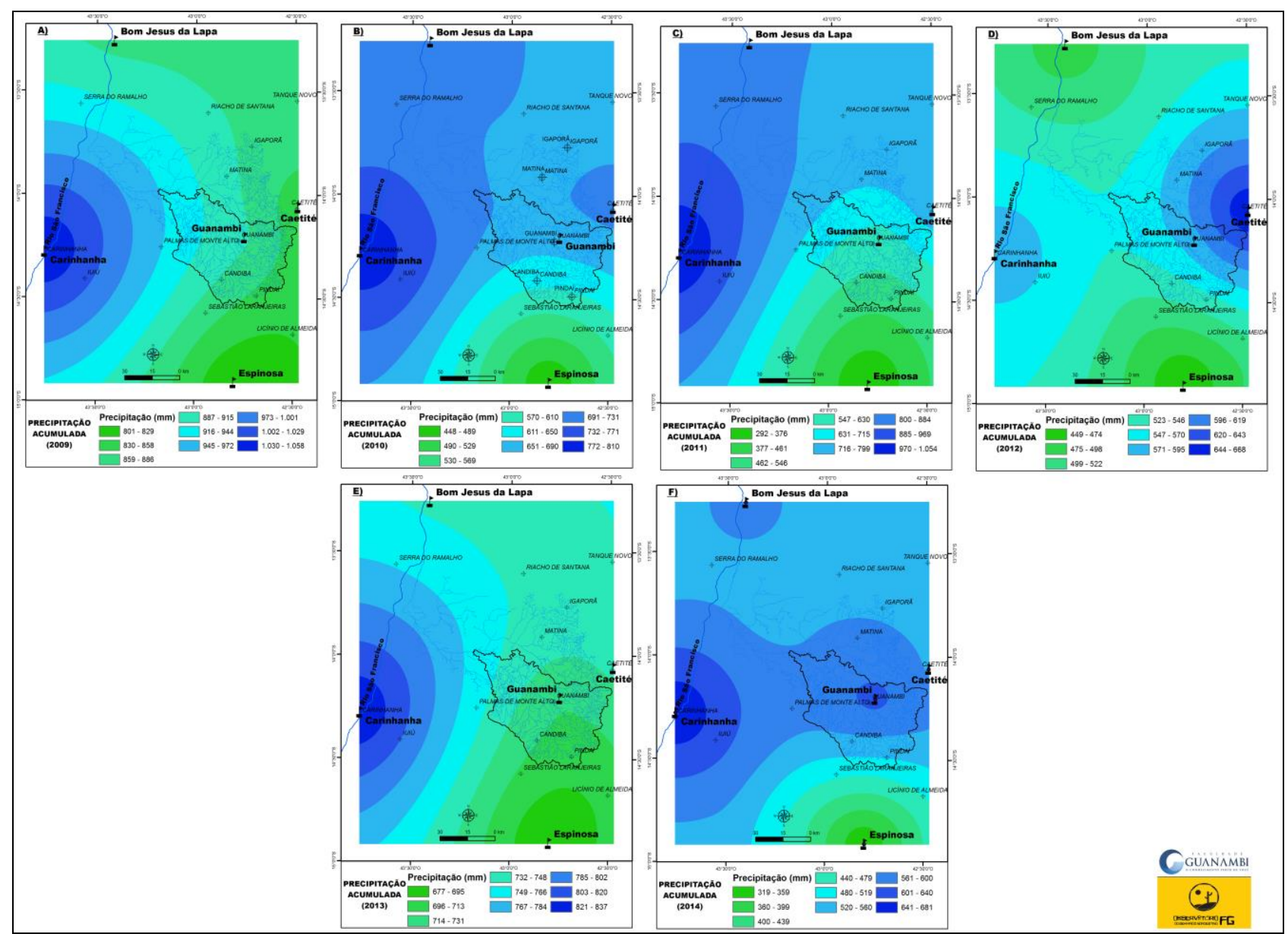

Figura 5. A) Precipitação acumulada anual em 2009; B) Precipitação acumulada anual em 2010; C) Precipitação acumulada anual em 2011; D) Precipitação acumulada anual em 2012; E) Precipitação acumulada anual em 2013; F)Precipitação acumulada anual em 2014. Microbacia do rio Carnaíba de Dentro e seu entorno (BA). Organização dos autores, 2016.

A Figura 6 representa a precipitação pluviométrica de todas as estações analisadas de 2009 a 2014. É relevante considerar que nos meses de Janeiro e fevereiro de 2011, na estação de Guanambi, ocorreram problemas (pane) nos sensores ou sinal de satélite, informações foram repassadas pelo INMET. Desse modo, a representação gráfica indica um período de estiagem iniciado a partido mês de abril, sendo os meses de maio, junho, julho, agosto e setembro a escassez de chuvas (Figura 06). Percebe-se valores bruscos de precipitação nos meses de outubro (2009), 
novembro (2012) e Dezembro (2013). Essas precipitações são caracterizadas como chuvas torrenciais isoladas em regiões semiáridas (JUNIOR; ALMEIDA, 2012).

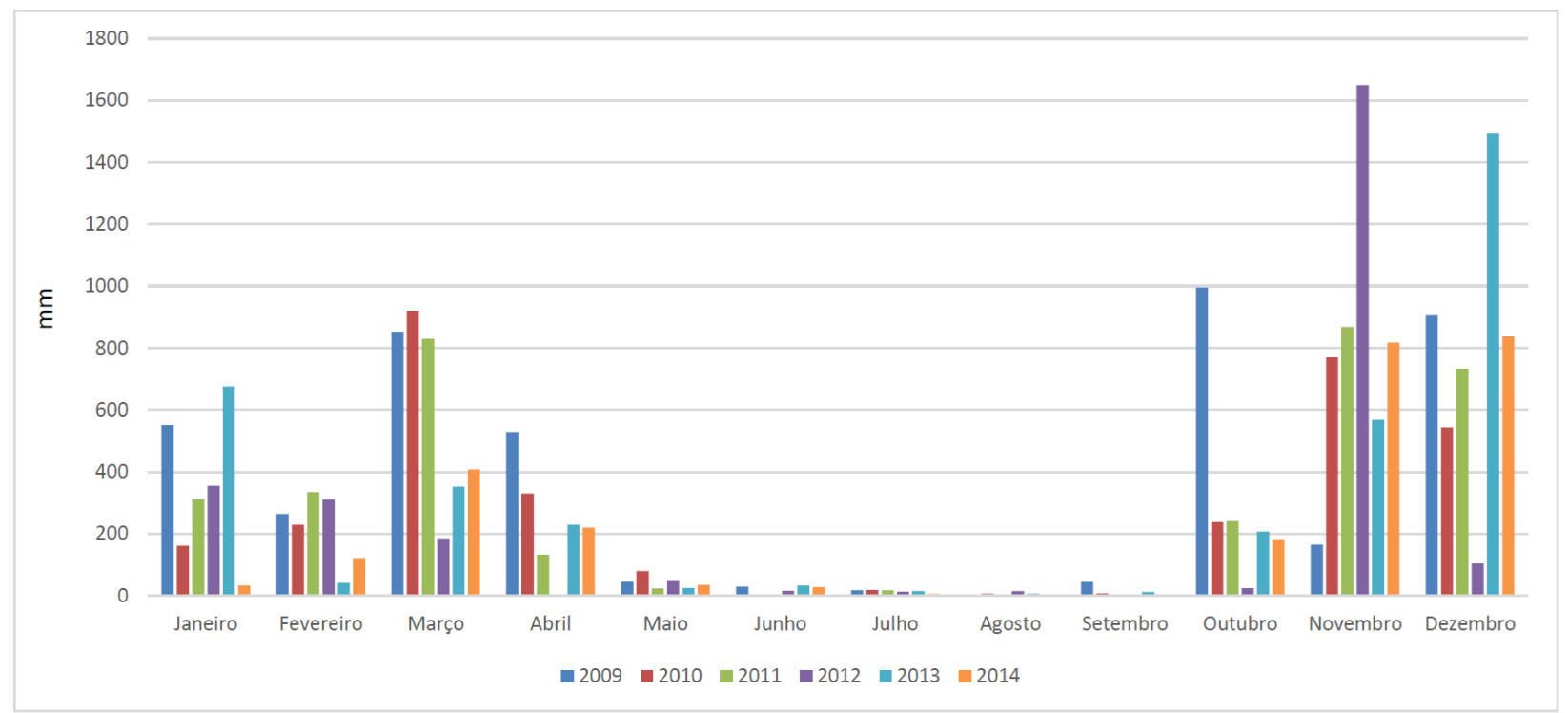

Figura 6. Gráficos de precipitações mensais - 2009 a 2014 Organização dos autores, 2016

Também variações nas formas de relevo são apresentadas na paisagem da área de estudo. De tal modo que as estações de Bom Jesus da Lapa e Carinhanha localizam-se na planície do rio São Francisco, próximo à margem da calha desse rio. Já a estação meteorológica de Caetité encontra-se instalada na Serra do Espinhaço e a estação meteorológica de Guanambi ao sopé dessa formação geomorfológica. A estação meteorológica de Espinosa apresenta-se entre a Serra do Espinhaço a leste e uma formação rochosa a oeste dessa mesma formação geomorfológica. A Figura 07 destaca o Modelo Digital de Elevação - MDE com a distribuição espacial das estações meteorológicas.

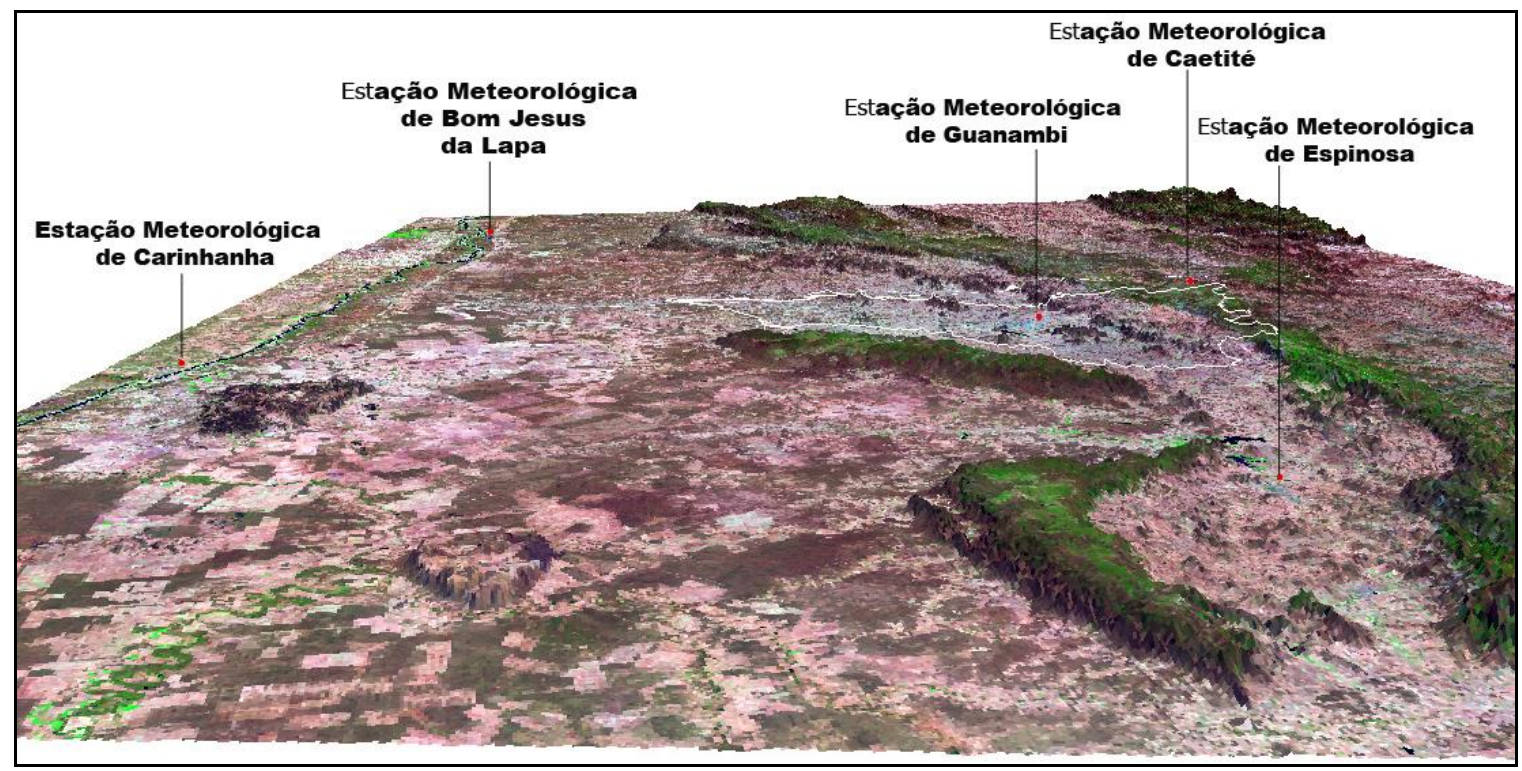

Figura 7. Modelo de elevação da área de estudo

Org.: CLEMENTE, Carlos Magno Santos, 2016 
Na microbacia do rio Carnaíba de Dentro, apresentam-se os reservatórios artificiais da Barragem de Ceraíma, do Poço do Magro, reservatório naturais e a área urbana mais substancial da região (Cidade de Guanambi (BA). Isso implica em maiores atenções para conservação e recuperação do Rio Carnaíba de Dentro, entre outros indicadores, são dois fatores de impacto negativo para perenidade do rio e manutenção da vida biológica. Principalmente pelo longo período de estiagem caracterizado no histórico de precipitação pluviométrica da microbacia do rio Carnaíba de Dentro. Esses são alguns atributos que contribuíram para o stress no ciclo hidrológico (ALBUQUERQUE FILHO, et al, 2010). A Figura 8 apresenta a localização dos reservatórios artificiais e a cidade de Guanambi (BA).

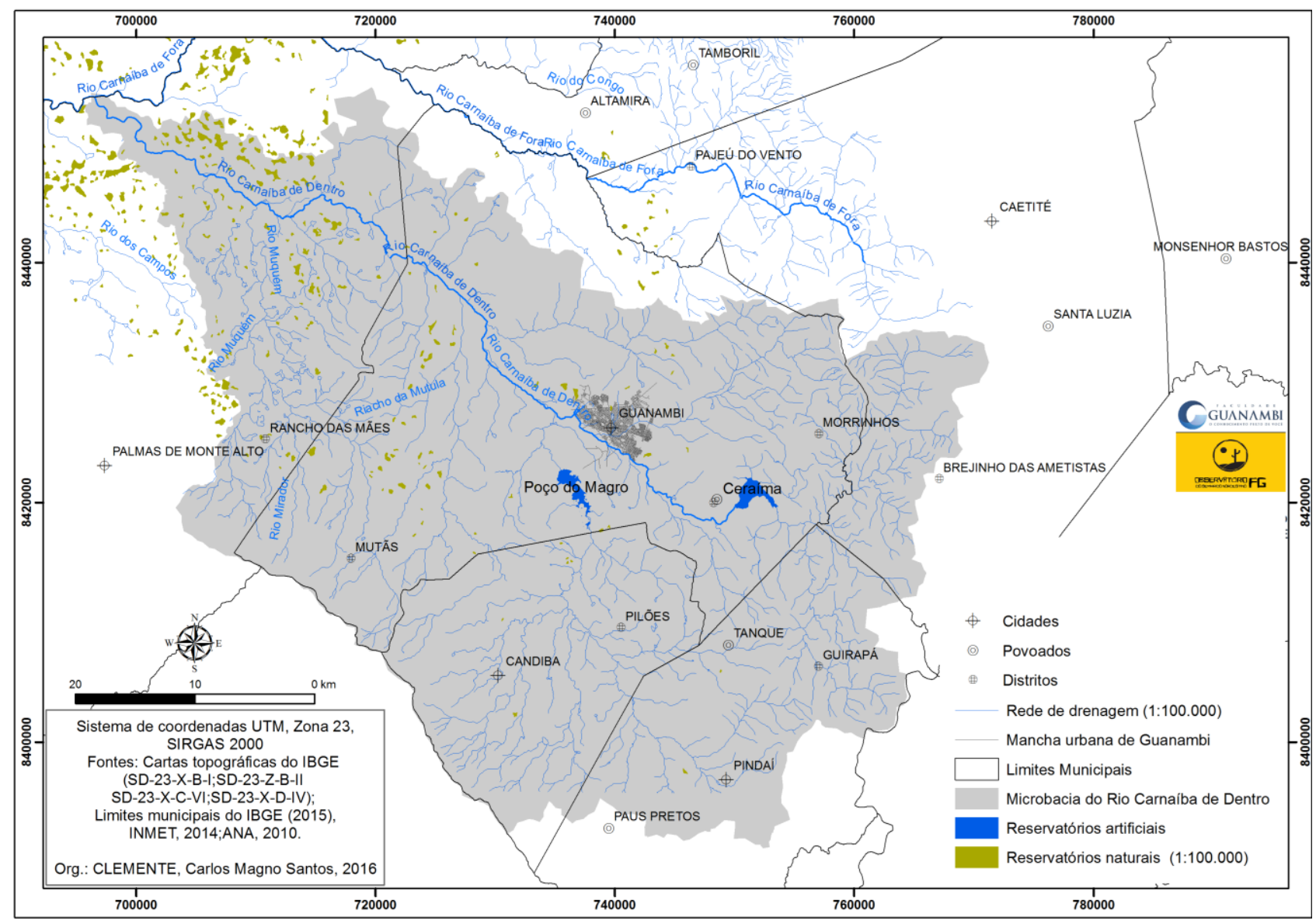

Figura 8. Localização dos reservatórios artificiais, naturais e mancha urbana de Guanambi (BA). Org.: CLEMENTE, Carlos Magno Santos, 2016

Percebe-se dentro e no entorno da microbacia hidrográfica do rio Carnaíba de Dentro irregularidade espaço-temporal na distribuição de chuvas, pois há elevados valores de precipitação pluviométrica há oeste da microbacia (Carinhanha) e baixos valores ao sul da microbacia (Divisa estadual Minas e Bahia, Espinosa - MG). Um bom exemplo foi no ano de 2011 em que ocorreu uma precipitação acumulada de $1.054 \mathrm{~mm}$ nas proximidades do município de Carinhanha, no entanto, 291,3 mm na divisa estadual Minas e Bahia (município de Espinosa - MG) (Figura 04). 
Nesse contexto, a irregularidade espacial e temporal na microbacia do rio Carnaíba de Dentro segue uma coerência de outras regiões do semiárido, pela concentração de chuvas e irregularidade da distribuição no espaço geográfico. Como alerta Rebouças (1997), a precipitação pluviométrica no semiárido nordestino, pode ocorrer em um mês ou distribuídas de forma irregular 3-5 meses chuvosos no ano. Ainda, de acordo com Junior e Almeida (2012), são peculiares a descontinuidade espaço-temporal no regime de chuvas em algumas regiões semiáridas, ou seja, valores discrepantes de precipitação pluviômetros em localizações não muito distantes. Vale ressaltar que fatores como elevados albedos, Zona de convergência Intertropical - ZCIT, linhas de instabilidades são alguns fenômenos que atuam na irregularidade espaço-temporal da distribuição de chuvas no semiárido nordestino (VIANELO; ALVES, 1991; PEREIRA; CAVALCANTI, 2014). Para Junior e Almeida (2012), a irregularidade do regime de chuvas no semiárido ocasiona a concentração de chuvas em 2 meses e outros meses com chuvas torrenciais isoladas.

Em relação aos aspectos ambientais, interferências antrópicas da microbacia do Rio Carnaíba de Dentro acarretaram impactos na drenagem do limite natural. Dentro esses fatores, a constituição dos reservatórios artificiais (nomeados como represa de Ceraíma e Poço do Magro) e a expansão urbana desordenada da cidade Guanambi (BA). A constituição de barragens ocasiona reflexo na rede de drenagem, bem como alterações no ambiente aquático, terrestre e físico, ou seja, modificação na dinâmica do mecanismo natural (ALBUQUERQUE FILHO, et al, 2010). No âmbito da urbanização sem planejamento, aspectos como falta do tratamento do esgoto, impermeabilização do solo, canalização dos rios e a ocupação do solo nas margens dos rios são principais problemas da poluição das águas urbanas (TUCCI, 2008). Vale ressaltar a estação de Caetité, que se localiza na Serra do espinhaço e próximos há nascentes da microbacia analisada.

Nessa perspectiva, o presente estudo chama atenção para a preservação do ambiente natural em áreas de nascentes e de suas matas ciliares na microbacia do rio Carnaíba de Dentro, principalmente, para melhor eficácia da dinâmica hidrológica. As Áreas de Preservação Permanente - APP apresenta uma função ambiental relevante para a preservação dos ecossistemas, pois potencializa a conservação dos recursos hídricos, o equilíbrio geológico, a diversidade biológica, a preservação dos solos e consequentemente asseverar a qualidade de vida das populações humanas (SCHÄFFER, et al., 2011).

Outra temática relevante refere-se ao saneamento básico, pois influência diretamente no meio ambiente e na qualidade de vida das populações urbana e rural. A lei $\mathrm{n}^{\mathrm{o}} 11.445$, de 5 de janeiro de 2007 estabelece como componentes bases para saneamento básico, o abastecimento de água potável, esgotamento sanitário, limpeza urbana e manejo de resíduos sólidos e a drenagem e manejo das águas pluviais. No que se concerne a bacias hidrográficas, a lei supracitada dispõe sobre a compatibilidade dos planos de saneamento básico com os documentos de gestão de bacias 
hidrográficas e sugere esse limite natural como unidade de referência para o planejamento ambiental.

Com isso, conhecer a dinâmica do regime da precipitação pluviométrica em determina bacia hidrográfica é um mecanismo relevante para planejamento para o uso racional água. Principalmente na região do semiárido brasileiro, em que as secas prolongadas e a fragilidade política voltadas para o desenvolvimento social acompanharam o histórico de ocupação territorial marcaram essa região. Além disso, as análises com intervalos temporais mais amplos (30 anos) são indicadas para compreender as alterações climáticas (WANDERLEY et al, 2013). Devido às diferenciações das formas de relevo e da distribuição irregular de precipitação pluviométrica na área de estudo, a presente pesquisa destaca a relevância do desenvolvimento de estudos sobre a geomorfologia climática e a Teoria dos Sistemas na microbacia do Rio Carnaíba de Dentro e seu entorno. A Teoria dos Sistemas que destacam entendimento dos fluxos de energias, matérias e as relações dos equilíbrios naturais (AMARAL; ROSS, 2009).

\section{CONSIDERAÇÕES FINAIS}

Na microbacia do rio Carnaíba de Dentro baixos indicadores de precipitação pluviométrica, em relação as normais climatológicas do INMET, foram detectados, principalmente, na divisa de Minas Gerais com Bahia, em especifico estação meteorológica de Espinosa (MG). Porém, destacam-se valores de precipitação acumulada elevados no entorno das cidades de Carinhanha (BA) e Iuiu (BA), locais próximos ao rio São Francisco. Diante dos apontamentos, a presente pesquisa abaliza para uma irregularidade espaço-temporal da distribuição de chuvas na microbacia do Rio Carnaíba de Dentro e seu entorno, nos anos de 2009 a 2014. Além disso, valores bruscos de precipitação nos meses de outubro (2009), novembro (2012) e dezembro (2013) com características de chuvas torrenciais, ou seja, a concentração de chuvas em um intervalo curto (poucas horas elevado volume) nos meses supracitados.

Ainda o estudo elucida uma reflexão para a preservação e recuperação dos ecossistemas em áreas de nascentes, suas matas ciliares e maior rigor com o saneamento básico na microbacia do rio Carnaíba de Dentro. Isso implica na melhoria da eficiência da dinâmica hidrológica e consequentemente na qualidade de vida das pessoas.

Logo, o estudo é uma forma de contribuição sistemática e exploratória para a melhor compreensão dos recursos hídricos na microbacia do rio Carnaíba de Dentro, facilitando a adoção de condutas científicas e políticas públicas diversas. Ainda evidencia-se a relevância da utilização da bacia Hidrográfica como unidade de gestão e a compreensão do regime da precipitação pluviométrica para o planejamento ambiental e a utilização dos recursos hídricos de forma racional. 


\section{AGRADECIMENTOS}

Agradecemos a Faculdade Guanambi - FG pelo apoio a pesquisa e ensino. Somos gratos ao Observatório FG do Semiárido Nordestino pelo suporte técnico e intelectual. Agradecemos ao Instituto Nacional de Meteorologia - INMET pela disponibilização dos dados de precipitação pluviométrica de 2009 a 2014.

\section{REFERÊNCIAS}

AB'SÁBER, A.N,. Dossiê Nordeste seco; Sertões e sertanejos: uma geografia humana sofrida. Estudos Avançados. São Paulo. v.13, (36), p. 7-59, 1999. Disponível em < http://www.revistas.usp.br/eav/article/view/9474/11043>. Acessado em 02 de dezembro de 2016.

ALBUQUERQUE FILHO, J.L; SAAD, A.R; ALVARENGA, M.C. Considerações acerca dos impactos ambientais decorrentes da implantação de reservatórios hidrelétricos com ênfase nos efeitos ocorrentes em aqüíferos livres e suas consequências. Geociências, São Paulo, UNESP. v. 29, n. 3, p.355-367, 2010. Disponível em < http://www.periodicos.rc.biblioteca.unesp.br/index.php/geociencias/article/view/5390/4228. Acessado em 02 de dezembro de 2016.

AMARAL, R; ROSS, J, L.S. As unidades ecodinâmicas na análise da fragilidade ambiental do parque estadual do morro do diabo e entorno. Teodoro Sampaio/SP. GEOUSP - Espaço e Tempo. São Paulo. n²6, p.59-78, 2009. Disponível em http://www.revistas.usp.br/geousp/article/view/74128> Acessado em 02 de dezembro de 2016.

BRASIL. Presidência da República. Lei no 11.445, de 5 de janeiro de 2007. Disponível em < https://www.planalto.gov.br/ccivil_03/_ato2007-2010/2007/lei/111445.htm>. Acessado em 02 de dezembro de 2016.

COSME, António. Projeto em Sistemas de Informação Geográfica. $1^{\circ}$ ed. Lisboa. Ed Líder.. 2012. p.849

DIAS, L.S.O.; ROCHA, G.A.; BARROS, E.U.A.; MAIA, P.H.P. Utilização do radar interferométrico para delimitação automática de bacias hidrográficas. Bahia Análise \& Dados, Salvador, v. 4, n.2, p.265-271, 2004.

INSTITUTO BRASILEIRO DE GEOGRAFIA E ESTATÍSTICA - IBGE. Censo da população do Brasil, 2010. Disponível em: < http://www.ibge.gov.br/home>. Acessado em 20 Abri. 2015.

INSTITUTO BRASILEIRO DE GEOGRAFIA E ESTATÍSTICA - IBGE. Manual Técnico da Vegetação Brasileira, 2012. Disponível em: < http://biblioteca.ibge.gov.br/visualizacao/livros/liv63011.pdf >. Acessado em 06 Dezembro. 2016.

INSTITUTO NACIONAL DE METEOROLOGIA - INMET. Normais Climatológicas do Brasil, 1992. Disponível em 〈http://www.inmet.gov.br/portal/index.php?r=clima/normaisclimatologicas $>$. Acessado em 24 abril de 2015.

INSTITUTO NACIONAL DE PESQUISAS ESPACIAIS - INPE. Projeto TopoData. Disponível em http://www.dsr.inpe.br/topodata/index.php. Acessado em 27 abri. 2015.

JACOMINE, P.K.T.; CAVALCANTI, A.C.; FORIGA, R.A.; SILVA, F.B.R.; BURGOS, N.; 
MEDEIROS, L.A.R.; LOPES, O.P.; MELO FILHO, H.F.R.; PESSOA, S.G.P.; LIMA, P.C. Levantamento exploratório-reconhecimento de solos do Norte de Minas Gerais (área de atuação da SUDENE). Recife: EMBRAPA-SUDENE, 1979. p.407.

JÚNIOR, J.B.C; ALMEIDA, H.A. Influência do fenômeno El-Niño sobre o regime pluvial na microrregião de Sousa, PB. Revista Geonorte. Edição Especial. v.2, n.4,p. 904 - 915. 2012. Disponível em < http://www.periodicos.ufam.edu.br/revista-geonorte/article/view/2155/2021> acessado em 03/12/2016.

LEITE, M.E; ROSA, R. Geografia e geotecnologias no estudo urbano. Caminhos da Geografia (UFU Online). Uberlândia. v 17, n 1,p 179 - 186. 2002. Disponível em < http://www.seer.ufu.br/index.php/caminhosdegeografia/article/view/15396/8695>. Acessado em 03/12/2016.

MINISTÉRIO DO MEIO AMBIENTE - MMA. Biomas Brasileiros. 2004. Disponível em: <http://www.mma.gov.br/>. Acessado em 25 Abri. 2015.

MOLION, L.C.B; BERNADO, S.O. Uma revisão da dinâmica das chuvas no Nordeste brasileiro. Revista Brasileira de Meteorologia. v.17, n.1, p.1-10 ,2002. Disponível em < http://www.rbmet.org.br/port/revista/revista_artigo.php?id_artigo=548>. Acessado em 03/12/2016.

PEREIRA, R.C.G., CAVALCANTI, E.P. Regimes pluviométricos da região NE do Brasil: uma análise dos dados climatológicos de 1961 a 1990 utilizando ACP. Revista de Geografia (UFPE). V. 31, n. 2, p. 248-257 2014. Disponível em < http://www.revista.ufpe.br/revistageografia/index.php/revista/article/view/649/568>. Acessado em $04 / 12 / 2016$.

PORTO, M.F.; PORTO, A.R.L.L. Gestão de Microbacias hidrográficas. Estudos Avançados. São Paulo. v.22. n.63, 43-60, 2008. Disponível em < http://www.scielo.br/pdf/ea/v22n63/v22n63a04.pdf>. Acessado em 04/12/2016.

PROGRAMA DE CONSERVAÇÃO E UTILIZAÇÃO SUSTENTÁVEL DA DIVERSIDADE BRASILEIRA - PROBIO. Levantamento da cobertura vegetal do uso do solo do bioma caatinga, 2004. Disponível em < http://mapas.mma.gov.br/geodados/brasil/vegetacao/vegetacao2002/caatinga/documentos/relatorio_ final.pdf>. Acessado em 06/12/2016.

SANTOS, E.; MATOS, H.; ALVARENGA, J.; SALES, M.C.L. A seca no nordeste no ano de 2012: relato sobre a estiagem na região e o exemplo de prática de convivência com o semiárido no distrito de Iguaçu/Canindé-CE. Revista Geonorte, Edição Especial 2, V.1, n.5, p.819 - 830, 2012.

SCHÄFFER, W.B; ROSA, M.R; AQUINO, L.C.S; MEDEIROS, J.D. Áreas de Preservação Permanente e Unidades de Conservação \& Áreas de Risco. O que uma coisa tem a ver com a outra? Relatório de Inspeção da área atingida pela tragédia das chuvas na Região Serrana do Rio de Janeiro. Brasília: Ministério do Meio Ambiente - MMA, 2011. p.97.

SIMIONI, J. P.D; ROVANI, F.F.M; IENSSE, A.C; WOLLMANN, C.A. Caracterização da Precipitação Pluviométrica na Microbacia Hidrográfica do Rio Ibicuí, RS. Revista do Departamento de Geografia - USP, v.28, p. 112-133, 2014. Disponível em < http://www.revistas.usp.br/rdg/article/view/90008/92798>. Acessado em 04/12/2016. 
SILVA, A. B. Políticas públicas e tecnologias sociais para convivência com o semiárido no Cariri Paraibano. In: XVII Encontro Nacional de Geógrafos, 2012, Belo Horizonte - MG. Anais do XVII Encontro Nacional de Geógrafos. Belo Horizonte - MG, 2012. v. 01. p. 01-11. Disponível em < http://eng2012.agb.org.br/consulta?searchword=cariri\&ordering=newest\&searchphrase=all > . Acessado em 04/12/2016.

SILVA, V.P. R; PEREIRA, E.R. R; AZEVEDO, P.V;SOUSA, F.A. S.; SOUSA, I.F. Análise da pluviometria e dias chuvosos na região Nordeste do Brasil. Revista Brasileira de Engenharia Agrícola e Ambiental. v.15, n.2, p.131-138, 2011. . Disponível em < http://www.scielo.br/pdf/rbeaa/v15n2/v15n02a04.pdf>. Acessado em 04/12/2016.

SOBRINHO, T.A; OLIVEIRA, P.T. S.; RODRIGUES, D.B. B.; AYRES, F.M. Delimitação automática de bacias hidrográficas utilizando dados SRTM. Engenharia Agrícola. v.30, n.1, p.4657, 2010.

REBOUÇAS, A.C. Água na região Nordeste: desperdício e escassez. Estudos avançados. São Paulo. v.11, p.127-154, n 29, 1997.

TUCCI, C.E. M. Águas urbanas. Estudos avançados. São Paulo. v.22, p.97-112,n63, 2008 VALERIANO, M. M.; ROSSETTI, D. F. Topodata: Brazilian full coverage refinement of SRTM data. Applied Geography (Sevenoaks), v. 32, p. 300-309, 2012.

VIANELLO, R.L. E ALVES, A.R. Meteorologia básica e aplicações. Viçosa, UFV. $2^{\circ}$ ed, 1991. p.449.

WANDERLEY H.S.; SEDIYAMA, G.C. , JUSTINO, F.B., ALENCAR, L.P.; DELGADO, R.C. Variabilidade da precipitação no Sertão do São Francisco, estado de Alagoas. Revista Brasileira de Engenharia Agrícola e Ambiental. Campina Grande, PB. v.17, n.7, p.790-795, 2013.

U.S. Geological Survey. Earth Explorer, Landsat-8. Disponível em <http://earthexplorer.usgs.gov/>. Acessado em 20 abril 2015.

Trabalho enviado em 04/11/2016 Trabalho aceito em 18/12/2016 